\title{
EXPLORING THE TWILIGHT ZONE: A MULTI-SENSOR APPROACH
}

\author{
JONATAN DA SILVA ${ }^{1,2^{*}}$, FERNANDO G. MORAIS ${ }^{1,3}$, MARCO A. FRANCO ${ }^{3}$, FÁBIO J. S. LOPES ${ }^{1}$, GREGORI DE A. \\ ARRUDA $^{1}$, ALEXANDRE C. YOSHIDA ${ }^{1,4}$, ALEXANDRE CORREIA ${ }^{3}$ AND EDUARDO LANDULFO ${ }^{1}$ \\ ${ }^{1}$ Centro de Lasers e Aplicações (CLA), Instituto de Pesquisas Energéticas e Nucleares - IPEN, Brasil. \\ ${ }^{2}$ Centro de Ciências Exatas e das Tecnologias, Universidade Federal do Oeste da Bahia - UFOB, Brasil \\ ${ }^{3}$ Instituto de Física - Universdiade de São Paulo - USP-Brasil \\ ${ }^{4}$ Instituo de Ciências Exatas e Naturais do Pontal, Universdidade Federal de Uberlândia - UFU, Brasil \\ *Email: jonatansilva@usp.br
}

\begin{abstract}
This study shows a set of analysis of measurements from ground-based and satellite instruments to characterize the twilight zone (TLZ) between clouds and aerosols in São Paulo, Brazil. In the vicinity of clouds turbulence measurements showed an intense upward movement of aerosol layers, while sunphotometer results showed an increase in aerosol optical depth, and lidar measurements showed an increase in the backscatter vertical profile signal.
\end{abstract}

\section{INTRODUCTION}

The Twilight Zone concept was introduced more than 10 years ago as a mean to describe the transition from cloud-free regions in the atmosphere to cloudy environments [1]. The TLZ represents the region where clouds and aerosols interact with the presence of forming and evaporating clouds fragments and hydrated aerosol particles [1]. Radiation fluxes through the TLZ can extend from meters to tens of kilometers, are highly sensitive local conditions and still have uncertainties when observed from space or ground-based instruments.

Several studies demonstrate an increase of cloud cover and cloud optical depth correlated with an increase of aerosol optical depth (AOD) in areas near clouds. The city of São Paulo in Brazil is among the largest and most polluted cities in the world, where we examined columnar aerosol optical properties both on areas nearby and far away from clouds, using a ground-based lidar system operating in synergy with an Aerosol Robotic Network (AERONET) sunphotometer [3], satellite measurements, an all-sky camera, and a pyranometer. We have identified a subgroup of measurements carried out between March and
November of 2018, which presents cloud field structures compatible with the TLZ definition. Here we present preliminary results for the $10^{\text {th }}$ April 2018 using a multi-sensor approach analysis.

\section{INSTRUMETATION AND METHODOLOGY}

\subsection{The lidar system}

The lidar system is located at Center for Laser and Applications (CLA) of the Nuclear and Energy Research Institute (IPEN) (23.560 S, $46.740 \mathrm{~W}$, $740 \mathrm{~m}$ above sea level) [4]. The lidar system is a multiwavelength Raman $\left(3 \beta+2 \alpha+\mathrm{H}_{2} \mathrm{O}\right)$ configured in a monostatic biaxial alignment pointing vertically to the zenith, operating with a laser energy per pulse of about 600,400 and 230 $\mathrm{mJ}$ at 1064,532 and $355 \mathrm{~nm}$, respectively, at a repetition rate of $10 \mathrm{~Hz}$ and pulse duration of approximately $5 \mathrm{~ns}$.

\subsection{AERONET sunphotometer, satellite retrievals pyranometer and all-sky camera}

AERONET is a network of automated sun and sky radiometers that has been working for more than 25 years continuously, maintaining a readily accessible public domain database of aerosol optical, microphysical and radiative properties for aerosol research and characterization, validation of satellite retrievals, and synergism with other databases. This network provides observations of spectral AOD, inversion products, and columnar precipitable water in diverse aerosol regimes [3]. The Advanced Baseline Imager (ABI) aboard the Geostationary Operational Environmental Satellite (GOES-16) retrieves the AOD at $550 \mathrm{~nm}$ over land during daytime every 15 minutes. The MS-80 pyranometer measures the global solar 
radiation incident on the Earths surface, in a spectral range of 285 to $3000 \mathrm{~nm}$, with a sensitivity of 7 to $14 \mu \mathrm{V} / \mathrm{W} / \mathrm{m}^{2}$. The Automated Sky Imaging System (ASI) model J1006 [5] is installed within five meters of the lidar system. This system is made up of a fisheye lenses, software for data acquisition and analysis. The measurements are taken every five minutes with a resolution of 1600 by 1200 pixels.

\subsection{Methodology}

The lidar measurements allowed us to identify from a 2018 dataset occurrences of cloud field structures and free-cloud zones compatible with the TLZ definition. These days were filtered by correlative measurements retrieved by the AERONET sunphotometer, GOES-16 AOD retrievals, and the all-sky camera images. We selected for this case study the lidar measurements for $10^{\text {th }}$ April 2018 which were performed with at an acquisition rate of $2 \mathrm{~s}$ (so-called turbulence measurement). Using the turbulence measurement approach [7] it was possible to analyze high order moments of scattering profiles, such as the skewness, that describes descending and ascending movements of the aerosol parcels in the atmospheric boundary layer (ABL).

Retrieved data from GOES-16 satellite with a footprint of $24 \mathrm{~km}$ centered at the lidar station allowed the investigation of the AOD product. AOD variation has an impact in the all-sky camera red-green-blue (RGB) channel magnitudes, in this sense, some analysis was conducted by comparison of mean red-blue ratio (RBR) [5] with interpolated AERONET AOD at $532 \mathrm{~nm}$. The RBR image analysis allows classify cloud cover. The all-sky camera and sunphotometer are about 350 meters apart. All-sky images for $10^{\text {th }}$ of April were retrieved together with sunphotometer and lidar data. During this day the cloud covering was moderate (30-40\%), allowing mixed lidar measurements with clear and cloudy conditions identified by RGB image components [5].

In this context we apply the lidar system and the ASI to map and select possible TLZ scenarios, while the AERONET, GOES-16 and lidar products are used to study the aerosol optical properties in atmospheric regions far away and near the clouds (timewise and spacewise).

\section{RESULTS}

Cloud free and the cloudy regions, together with the temporal evolution of the boundary layer is presented in figure 1, that shows the range corrected signal (RCS) retrieved at $532 \mathrm{~nm}$ by the lidar station.

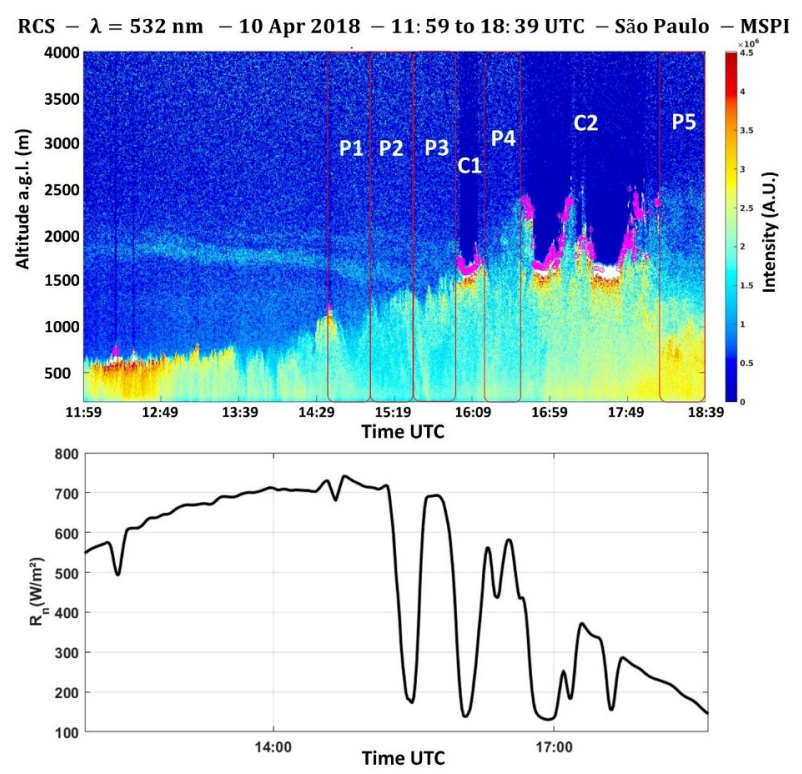

Figure 1: RCS at $532 \mathrm{~nm}$ retrieved by lidar station at $10^{\text {th }}$ of April of 2018 showing the clouds altitude, and below, the pyranometer profile showing radiation blockage by clouds.

Seven different scenarios are selected, $P_{1-5}$ are the cloud free conditions to be used to investigate TLZ conditions while the $C_{1}$ and $C_{2}$ are scenarios containing clouds around 1500 meters of altitude, represented in the figure by pink open circles.

The values of net radiation $\left(R_{n}\right)$ are estimated from the solar global irradiance $\left(R_{S d}\right)$ measured by a pyranometer using the following seasonal model: $R_{n}=a_{1} R_{S d}+b_{1}$, where $a_{1}=0.716$ and $b_{1}=-46.5$ $W / m^{2}$ [6]. Figure 1 also presents a comparison between $R_{n}$ and the lidar RCS. The sharp reductions in the $R_{n}$ signal along the day are in agreement with the presence of clouds detected by the lidar system. This information can help us to 
identify the optical thickness of different clouds, since the thicker the cloud, the deeper the valley in pyranometer profile.

The values of Skewness (S) obtained from RCSs are related with vertical aerosol movements, so that $S>0$ represents case of updrafts and $S<0$ indicates downdrafts. From the skewness profile in figure 2 it is possible to infer vertical movements of aerosol parcels. The predominance of atmospheric updrafts in periods $\mathrm{P}_{3}$ and $\mathrm{P}_{4}$ are an indication of the onset of shallow convection with aerosol contribution for cloud formation or the increasing of aerosol
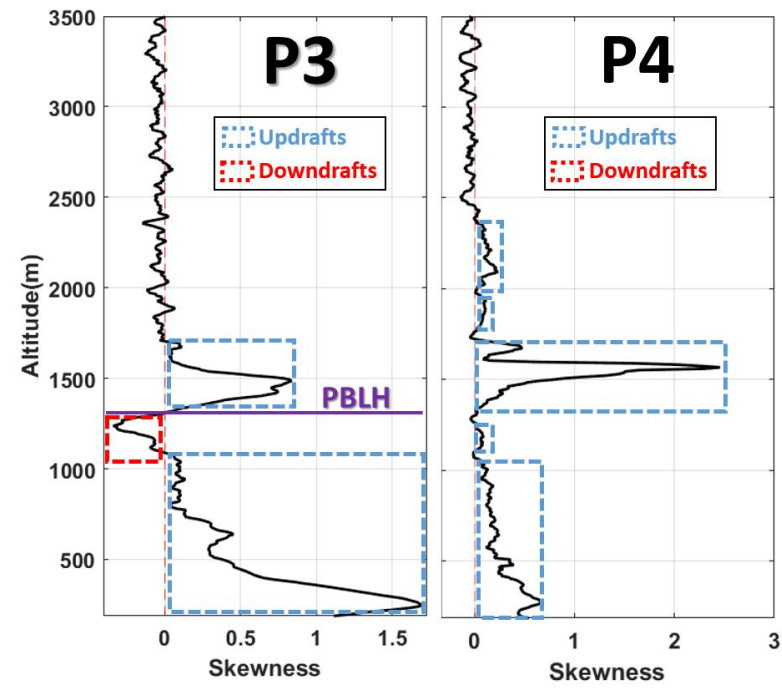

Figure 2: Skewness profile for two periods without clouds, P3 and P4 (fig.1).

quantity in the TLZ. In order to derive aerosol optical properties from the lidar measurements we retrieved the backscatter profile at $532 \mathrm{~nm}$ for each cloud-free conditions presented at figure 1 .

As can be seen in figure 3, the backscatter profile values, at the altitude region between 1.5 to 2.5 $\mathrm{km}$, are increasing as the profiles $P_{i}$ are approaching, in temporal scale, to the cloud profile $C_{1}$, which is an indication of the increased aerosol backscatter near clouds.

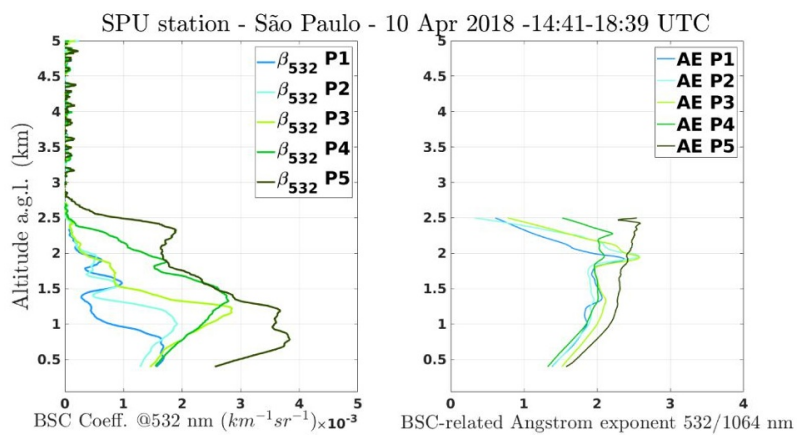

Figure 3: Lidar backscatter profile at $532 \mathrm{~nm}$ and backscatter-related Ångström exponent-532/1064nm.

The Backscattering-related Ångström exponent$532 / 1064 \mathrm{~nm}$ also suggests that the amount of aerosols increases near cloud profile $C_{1}$, and stay constant in the profiles $P_{4}$ and $P_{5}$, which is an expected behavior according to [2].

Further exploration of this feature should be undertaken with more cases where similar cloud and aerosol conditions are present. The AOD retrieved from AERONET (figure 4) are always below 0.50 indicating that the atmosphere is not heavily polluted, BSC-related Ångström exponent values about 2 indicate size distributions dominated by fine mode aerosols.

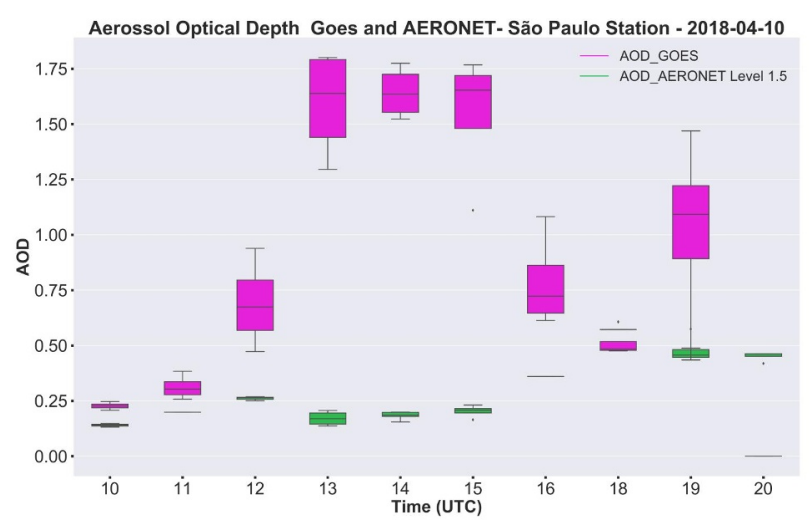

Figure 4: AOD retrievals from AERONET sunphotometer and Goes-16 Satellite.

Comparation between AOD from GOES-16 and AERONET reveals the GOES (Beta) product overestimates the "ground truth" AOD represented by AERONET, which can be due to enhanced solar radiation 3-D scattering in the TLZ cloud field [1]. 
The interpolated AOD values retrieved at $500 \mathrm{~nm}$ by the AERONET sunphotometer were correlated with the mean all-sky image RBR values for coincident measurement $(\approx 5 \mathrm{~min})$ of both instrument.

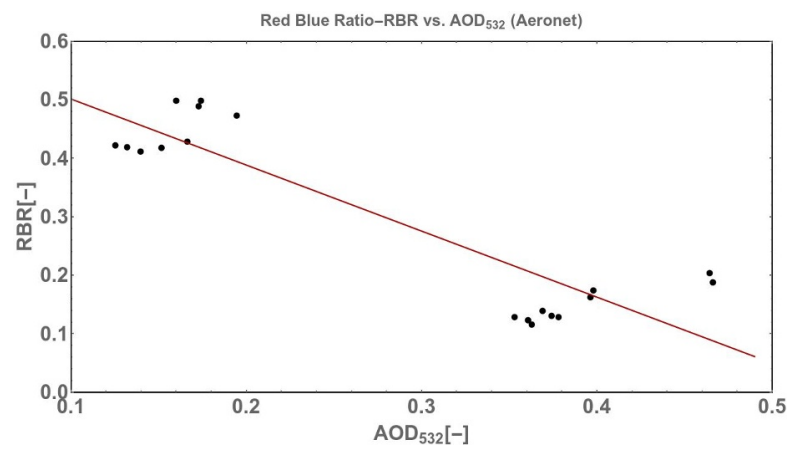

Figure 5: RBR-AOD at $532 \mathrm{~nm}$ correlation for $10^{\text {th }}$ of April for Sun zenith angles between $30^{\circ}$ and $70^{\circ}$.

The RBR-AOD correlation obtained was: $R B R=0.61-1.13 \tau_{532}$. The sky conditions allow the correlation between RBR and AOD value retrieval, which might be a trend to be inspected when other cases will be analyzed and reveal a stronger correlation.

\section{CONCLUSIONS}

We employed a set of ground-based and satellite measures to map twilight zone features. The AOD results retrieved by the AERONET revealed an aerosol increasing in the vicinity of clouds, whereas retrieved GOES-16 AOD showed significant biases. These AERONET results are corroborated by the skewness analysis, which presented an updraft movement of aerosol layers and an increase of aerosol load at in the TLZ. The same indication is shown by the backscatter profile at $532 \mathrm{~nm}$ and the BSC-related Ångström exponent retrieved by the lidar system.

\section{ACKNOWLEDGEMENTS}

The authors would like to acknowledge the FAPESP (Projects 15/12793-0, 18/03413-8, 152156/2018-6, and 10/15959-3) and CNPQ (Projects 152156/2018-6, 432515/2018-6, and 429112/2018-1).

\section{REFERENCES}

[1] Ilan Koren et al., Geophys. Res. Letters. 34, L08805 (2007), doi:10.1029/2007GL029253.

[2] W. Su et al., J. Geophys. Res., 113, D24202 (2008), doi:10.1029/2008JD010588.

[3] Brent Holben et al., Remote Sens. of envir., 66, 116 (1998),doi:10.1016/S0034-4257(98)00031-5

[4] Fábio J. S. Lopes et al., Remote Sens., 11, 195 (2019), doi:10.3390/rs11020195.

[5] M. S. Ghonima et al., Atmospheric Measurements Techniques, 11, 2881-2892 (2012), doi:10.5194/amt-52881-2012.

[6] Inmaculada Alados et al., Agricultural and Forest Meteorology, 116, 221-227 (2003), doi:10.1016/S0168-1923(03)00038-8.

[7] Gregori de A. Arruda et al., Atmos. Chem. Phys., 19, 1263-1280 (2019). doi:10.5194/acp-19-1263-2019. 